\title{
Validation of an Automatic Dose Injection System for Ictal SPECT in Epilepsy
}

\author{
Xavier Setoain ${ }^{1,2}$, Javier Pavía ${ }^{1-3}$, Eulalia Serés ${ }^{1}$, Ramiro Garcia ${ }^{1}$, Maria Mar Carreño ${ }^{4}$, Antonio Donaire ${ }^{4}$, Sebastià Rubí ${ }^{1}$, \\ Nuria Bargalló ${ }^{1,2}$, Jordi Rumià ${ }^{4}$, Teresa Boget ${ }^{2,4}$, Luís Pintor ${ }^{2,4}$, David Fuster ${ }^{1,2}$, and Francesca Pons ${ }^{1,2}$ \\ ${ }^{1}$ Diagnostic Imaging Centre, Hospital Clínic de Barcelona, Barcelona, Spain; ${ }^{2}$ Institut d'Investigacions Biomèdiques August Pi $i$ \\ Sunyer (IDIBAPS), Barcelona, Spain; ${ }^{3}$ Biomedical Research Networking Center in Bioengineering, Biomaterials and Nanomedicine \\ (CIBER-BBN), Barcelona, Spain; and ${ }^{4}$ Clinical Institute of Neurosciences, Hospital Clínic de Barcelona, Barcelona, Spain
}

\begin{abstract}
The purpose of our study was to evaluate the performance and clinical usefulness of an automated injector system (AIS) that administers an automated injection for ictal SPECT after calculating the volume of tracer to be injected over time. Methods: To test the AIS, repeated injections were performed at different times after tracer preparation. The clinical study consisted of 56 patients with drug-resistant, complex partial seizures. Tracer for ictal SPECT was injected using automated injection in 27 patients and manual injection (MI) in the remaining 29. Injection time $\left(T_{l}\right)$ was measured in seconds from seizure onset to the end of volume injection. The SISCOM (Subtraction Ictal Spect Co-registered to MRI) procedure was used to locate the epileptogenic seizure focus with SPECT. The definition of seizure focus was made by consensus of the epilepsy unit using conventional diagnostic methods. Results: During the experimental phase, there were no system failures, and the error in injected doses when using automated injection was lower than with MI. During the clinical phase, $T_{I}$ using manual injection was $41 \mathrm{~s}$ with a range of 14-103 s, compared with an AIS average of $33 \mathrm{~s}$ with a range of 19-63 s $(P<0.05)$. Ictal SPECT and SISCOM successfully localized the seizure focus in 21 of the 27 patients $(78 \%)$ by AIS and in 19 of the 29 patients $(65 \%)$ by $\mathrm{MI}(P=$ 0.14). Furthermore, nursing staff found the AIS method more convenient than the MI method. Conclusion: An AIS can improve the quality of work of the nursing staff in the neurology ward and allow a finer adjustment of the injection dose. Early results using an AIS would indicate a reduction in injection time and improved SPECT accuracy.
\end{abstract}

Key Words: epilepsy; ictal SPECT; automated injection system; 99mTc-HMPAO; SISCOM

J Nucl Med 2012; 53:324-329

DOI: 10.2967/jnumed.111.093211

$\mathbf{M}$ edically intractable complex partial seizures can be cured or improved using surgery, but accurate preoperative localization of the seizure focus is essential for complete

Received Jun. 27, 2011; revision accepted Sep. 26, 2011.

For correspondence or reprints contact: Xavier Setoain, Department of Nuclear Medicine, Hospital Clínic, C/Villarroel 170, 08036 Barcelona, Spain. E-mail: setoain@clinic.ub.es

Published online Jan. 12, 2012.

COPYRIGHT @ 2012 by the Society of Nuclear Medicine, Inc. seizure control. Videoelectroencephalogram (V-EEG) monitoring is the method of choice for localizing the seizure focus. However, a scalp electroencephalogram is often inadequate, especially for deep lesions or in rapidly spreading seizures, which it either fails to register or identifies as propagation rather than seizure onset (1). Structural and functional imaging procedures have been used to supplement electroencephalogram findings, avoiding invasive recordings with intracranial electrodes. MRI and ictal and interictal SPECT are the most frequently used procedures for localizing the seizure focus. Of these imaging techniques, ictal SPECT is the only one that can actually record the seizure onset zone (2).

Obtaining a good ictal SPECT study is not always easy, however, because a seizure is a dynamic process in which several brain regions can become involved sequentially $(3,4)$. ${ }^{99 m}$ Tc-labeled with hexamethylpropyleneamine-oxine $\left.{ }^{99 \mathrm{~m}} \mathrm{Tc}-\mathrm{HMPAO}\right)$ is injected during the epileptic seizure. Because of increased local cerebral blood flow during the seizure, a brain SPECT scan will show an increase in tracer uptake in the onset zone (5). If there is a delay in administering the tracer dose after seizure onset, the epileptic discharge can have already finished or propagated to distant cortical regions by the time of tracer injection $(1,6,7)$. A second limitation of ictal SPECT is the technically complex procedure required for injection.

To address these limitations, our unit developed an automatic injection system (AIS) that is activated from a remote-control module and injects the dose automatically when the patient goes into epileptic seizure. In this paper, we describe our experience with this AIS and the quality control procedures that were performed before its use on patients. The clinical usefulness of an automatic injection (AI) to inject ictal SPECT doses to epileptic patients was evaluated and compared with the manual injection (MI) method.

\section{MATERIALS AND METHODS}

\section{AIS}

The AIS consists of a 2-part module that communicates via radiofrequency and an injection pump containing the radioactive dose (Fig. 1). 

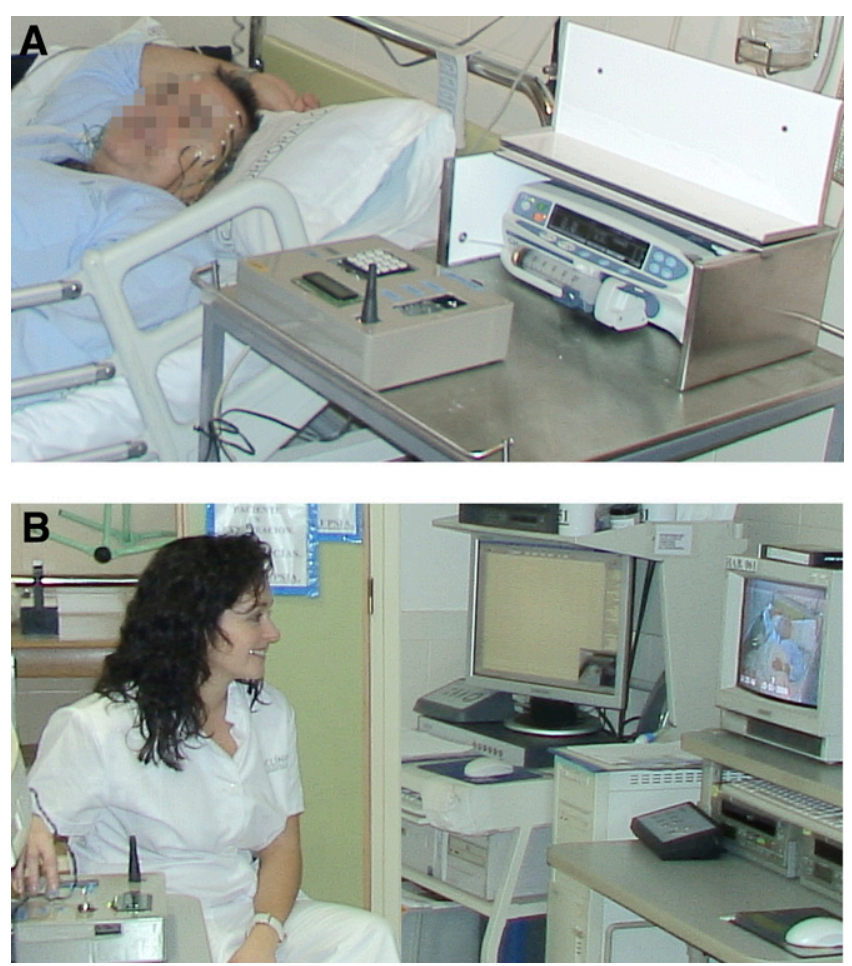

FIGURE 1. AIS (Asena GH-Alaris) pump containing radioactive dose, fixed inside lead-shielded box (A). Pump is connected to patient's forearm via pressure extension line filled with heparin and normal saline. Pump is also connected to pump-control module, which activates pump to inject precise volume of tracer to allow for radioactive decay. At electroencephalogram technicians' workstation (B), technician supervises V-EEG of patient and is ready to push remote-control module buttons when seizure is detected.

The remote-control module has 2 buttons to initiate injection and a security key. The module is installed in the electroencephalogram technicians' room. When technicians detect a seizure, they push the buttons to activate the AIS.

The pump-control module has a keyboard and display for the input data relating to dose calibration and the parameters required for tracer injection. The microprocessor calculates injected volume $\left(V_{I}\right)$ as a function of calibrated dose activity $\left(A_{c a l}\right)$ and calibration volume $\left(V_{\text {cal }}\right)$ at the time between calibration and injection. This module is located next to the patient's bed and connected to the pump. The data regarding calibration dose that are keyed into the pump-control module are the $A_{\text {cal }}$ in megabecquerels, $V_{c a l}$ in milliliters, and calibration time $\left(t_{c a l}\right)$. The parameters required for injection are the theoretic activity to be injected $\left(A_{I}\right)$, the dead volume $\left(V_{\text {dead }}\right)$ in the pressure extension line, and the dose expiration time.

Using all introduced data, we calculated the $V_{I}$ at time $t$ as:

$$
\left(V_{I}=\frac{A_{I} \times V_{c a l}}{A_{c a l} \times e^{-\lambda \cdot\left(t_{c a l}-t\right)}}+V_{\text {dead }},\right)
$$

where $\lambda$ is the disintegration constant for ${ }^{99 \mathrm{~m}} \mathrm{Tc}$, and $t$ the time of injection.

An Asena GH-Alaris infusion pump was chosen because it can be controlled by an RS232 serial interface and is already in use at our hospital for controlled infusion of medication. A radioactive tracer of ${ }^{99 \mathrm{~m}} \mathrm{Tc}-\mathrm{HMPAO}$ is placed in the pump in a syringe for bolus infusion. A pressure extension line filled with heparin and normal saline is connected directly from the syringe to a vein in the patient's forearm, prepared for intravenous injection. The injection pump is shielded in a 3-mm-thick lead-lined box.

\section{Experimental Phase}

System Control. Before its use in patients, a series of quality control tests was performed in the nuclear medicine laboratory. The tests were performed at 30-min intervals over a 4-h period, with 3 repetitions at each time. All tests were performed using a syringe filled with a standard activity $\left(A_{\text {cal }}\right)$ of $2,220 \mathrm{MBq}$ of ${ }^{99 \mathrm{~m} T c-p e r t e c h n e t a t e}$ in a volume $\left(V_{\text {cal }}\right)$ of $4 \mathrm{~mL}$.

\section{Clinical Phase}

Patients. The study included 56 consecutive prospective patients with drug-resistant complex partial seizures who were undergoing presurgical evaluation. Tracer injection for ictal SPECT was performed using AI in 27 patients (mean age, $33 \mathrm{y}$; 11 men and 16 women) and using MI in the remaining 29 patients (mean age, 36 y; 13 men and 16 women. All patients underwent ictal and interictal SPECT, V-EEG monitoring, and MRI. All subjects gave written informed consent before entering the study. The hospital's ethical committee approved the use of the AIS on patients.

V-EEG Monitoring and Seizure Focus Localization. V-EEG monitoring was performed in the epilepsy unit for $1 \mathrm{wk}$, using Nicolet BMSI 5000 equipment with 64 channels (8). Ictal scalp recordings were obtained using scalp electrodes placed in accordance with the international 10/20 system. Times of seizure onset and end of injection $\left(T_{I}\right)$ were obtained by reviewing the V-EEG. Seizure onset was defined as the time of earliest indication of auras or the beginning of rhythmic ictal discharge in the electroencephalogram. The seizure focus was defined by a consensus of the epilepsy unit by means of V-EEG monitoring, MRI, and clinical and neuropsychologic data.

Tracer Injection for SPECT. The programmed dose of $99 \mathrm{~m} \mathrm{Tc}-$ HMPAO was $925 \mathrm{MBq}$ for both injection systems. For MI, a 10$\mathrm{mL}$ syringe filled with stabilized ${ }^{99 \mathrm{~m}} \mathrm{Tc}-\mathrm{HMPAO}(138 \mathrm{MBq} / \mathrm{mL})$ was stored in a lead container beside the patient's bed. MI of the ictal SPECT was performed by an experienced nurse, trained to inject radioactive material, who was waiting for a seizure in the electroencephalogram technicians' room, next to the patient's room. The time taken by the electroencephalogram technician to identify a clinical seizure as confirmed in the electroencephalogram $\left(T_{S I}\right)$ is the time between seizure onset and the order to start injection. After this, the manual time $\left(T_{\text {manual }}\right)$ is the time it takes the nurse to go to the patient's room, open the lead-shielded container, take out the syringe containing ${ }^{99 \mathrm{~m}} \mathrm{Tc}-\mathrm{HMPAO}$, and intravenously inject a volume of $8 \mathrm{~mL}$, if seizure occurs in the first $2 \mathrm{~h}$, or $10 \mathrm{~mL}$, if it occurs between 2 and $4 \mathrm{~h}$ after tracer preparation. This injected volume guarantees a dose of between 820 and 1,042 $\mathrm{MBq}$ of ${ }^{99 \mathrm{~m}} \mathrm{Tc}-\mathrm{HMPAO}$. The $T_{I}$ for $\mathrm{MI}\left(T_{M I}\right)$ is the time from seizure onset to the end of injection, and the formula used was $T_{M I}=T_{S I}+T_{\text {manual }}$.

For AI, to reduce injection time, we minimized the volume to be injected, increasing the activity concentration during the tracer preparation $(9,10)$. A volume of $4 \mathrm{~mL}$ of stabilized ${ }^{99 \mathrm{~m}} \mathrm{Tc}-\mathrm{HMPAO}$ with a concentration of $539 \mathrm{MBq} / \mathrm{mL}$ was introduced in a syringe that was placed in the pump ready for the injection. When the technicians detected a clinical seizure, confirmed by electroencephalogram changes, they pushed the 2 buttons on the remotecontrol module $\left(T_{S I}\right)$. To calculate the $T_{I}$ for AI $\left(T_{A I}\right)$, the formula 


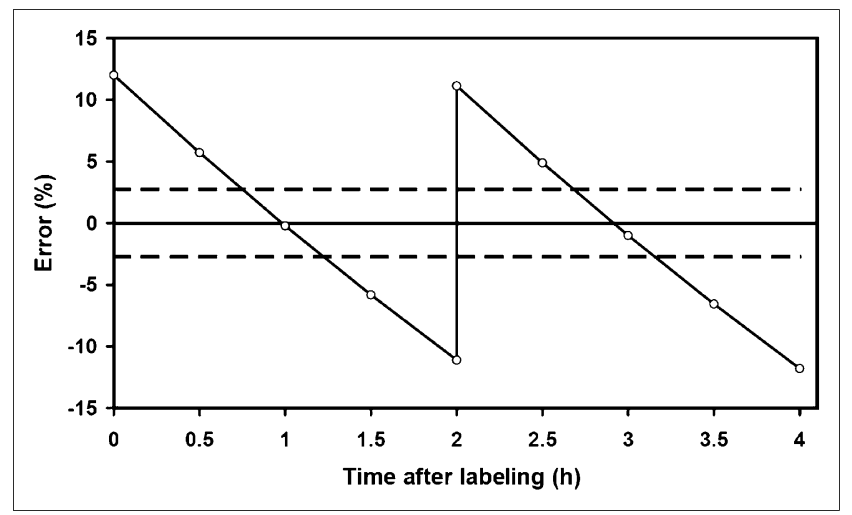

FIGURE 2. Continuous line shows theoretic error in dose administration (in \%) using $\mathrm{Ml}$ at different times (over 4-h period at 30-min intervals) after tracer preparation. Dashed line shows error confidence interval using Al.

used was $T_{A I}=T_{S I}+T_{\text {pump }}$, where $T_{\text {pump }}$ is the time required for the pump to inject $V_{I}$.

MRI and SPECT. MRI was performed using a 3-T unit (Tim Trio; Siemens) with a specific epilepsy protocol. Ictal and interictal studies were acquired with the same protocol, using a dual-head SPECT system (Infinia; GE Healthcare) with a lowenergy high-resolution parallel-hole collimator. To assess and accurately locate the epileptogenic seizure focus before surgery, we used the SISCOM (Subtraction Ictal Spect Co-registered to MRI) procedure (11-13) with our own customized software (focusDET). Software description and acquisition parameters for MRI and SPECT are set out in the supplemental data (supplemental materials are available online only at http://jnm.snmjournals. org).

Ictal SPECT and SISCOM images were analyzed by 2 experienced physicians who were unaware of the clinical and radiologic findings. SPECT localized the seizure focus when an increase of perfusion in the ictal SPECT images was confirmed by the SISCOM images. SPECT findings were compared with the seizure onset zone as determined by conventional diagnostic methods.

Statistical Analysis. To assess whether $T_{I}$ was higher with $T_{M I}$ than with $T_{A I}$ (unilateral hypothesis), a Student $t$ test for independent samples was used, and $P$ values of 0.05 or less were considered as significant. The ability of SPECT to localize the seizure focus with $\mathrm{AI}$ and with MI was compared using the $\chi^{2}$ test. For both injection procedures, the error in injected dose was calculated as a percentage at different times over a 4 -h period.

\section{RESULTS}

\section{Experimental Phase}

System Control. There was no system failure in any of the tests. When the AIS was used, the $V_{I}$ of ${ }^{99 \mathrm{~m}} \mathrm{Tc}-\mathrm{HMPAO}$ necessary to guarantee an injected dose of $925 \mathrm{MBq}$ was readjusted electronically from $3-4 \mathrm{~mL}$ over a 4 -h period. Because the injection rate for this pump is $0.333 \mathrm{~mL} / \mathrm{s}$, plus a dead time of $4 \mathrm{~s}$, the values of $T_{\text {pump }}$ ranged from 13 to 16 $\mathrm{s}$ (average, $14.5 \mathrm{~s}$ ). The error between $V_{I}$ and measured dose activity in the 24 tests performed was $1.4 \% \pm 0.7 \%$. Figure 2 shows the interval of confidence of this error.
TABLE 1

Clinical Data

\begin{tabular}{lcc}
\hline \multicolumn{1}{c}{ Parameter } & Al & MI \\
\hline Patients $(n=56)$ & 27 & 29 \\
Mean age \pm SD & $33 \pm 13$ & $36 \pm 14$ \\
Mesial temporal seizures $(n=17)$ & 7 & 10 \\
Neocortical seizures $(n=39)$ & 20 & 19 \\
MRI & & \\
\hline Normal & 6 & 4 \\
Mesial temporal sclerosis & 7 & 11 \\
\hline Focal MDC & 10 & 7 \\
\hline Malacia & 3 & 4 \\
\hline Atrophy & 0 & 2 \\
Tumor & 1 & \\
Seizure focus & & 14 \\
Temporal & 11 & 10 \\
\hline Frontal & 8 & 3 \\
Parietal & 1 & 0 \\
\hline Occipital & 1 & 2 \\
Temporoparietal & 5 & 0 \\
Hemispheric & 1 & \\
\hline
\end{tabular}

${ }^{*}$ Focal MDC = malformation of cortical development (17 patients), that includes focal cortical dysplasia (15 patients) and focal subependymal heterotopias (2 patients).

With MI, to compensate for radioactive decay of ${ }^{99 \mathrm{~m}} \mathrm{Tc}$, the volume is readjusted once during the 4-h period. Figure 2 also shows the theoretic error between programmed theoretic dose and injected dose with this readjustment, allowing a comparison of errors made by the 2 injection systems.

\section{Clinical Phase}

Patients. The most relevant clinical data, MRI findings, and clinical seizure focus localization are summarized in Table 1.

Tracer Injections for Ictal SPECT. $T_{I}$ values for each patient of the MI and AI groups are shown in Figure 3. Average $T_{M I}$ was $41 \pm 21 \mathrm{~s}$ (mean $\pm \mathrm{SD}$ ), with a range of $14-103 \mathrm{~s}$ (Fig. 3A), whereas the average $T_{A I}$ was $33 \pm 12 \mathrm{~s}$, with a range of 19-63 s. (Fig. 3B). Reduction in $T_{I}$ using AI was $8 \mathrm{~s}$ on average, and this difference was statistically significant $(P<0.05)$. With $\mathrm{MI}$, the average $T_{S I}$ was 19

TABLE 2

Features of Injection and Seizure of Ictal SPECT

\begin{tabular}{lccc}
\hline \multicolumn{1}{c}{ Parameter } & Al & MI & $P$ \\
\hline $\begin{array}{c}\text { Mean duration of } \\
\text { seizures } \pm \mathrm{SD}\end{array}$ & $68 \pm 49$ & $92 \pm 71$ & 0.14 \\
Aura & 5 & 4 & \\
Postictal injections & 7 & 3 & \\
$T_{S I}(\mathrm{~s})$ & $18 \pm 12$ & $19 \pm 22$ & 0.85 \\
$T_{\text {pump }}$ and $T_{\text {manual }}(\mathrm{s})$ & $15 \pm 1$ & $22 \pm 9$ & $0.0001^{\star}$ \\
$T_{I}(\mathrm{~s})$ & $33 \pm 12$ & $41 \pm 21$ & $0.035^{*}$
\end{tabular}

*Statistically significant at the $P<0.05$ level. 


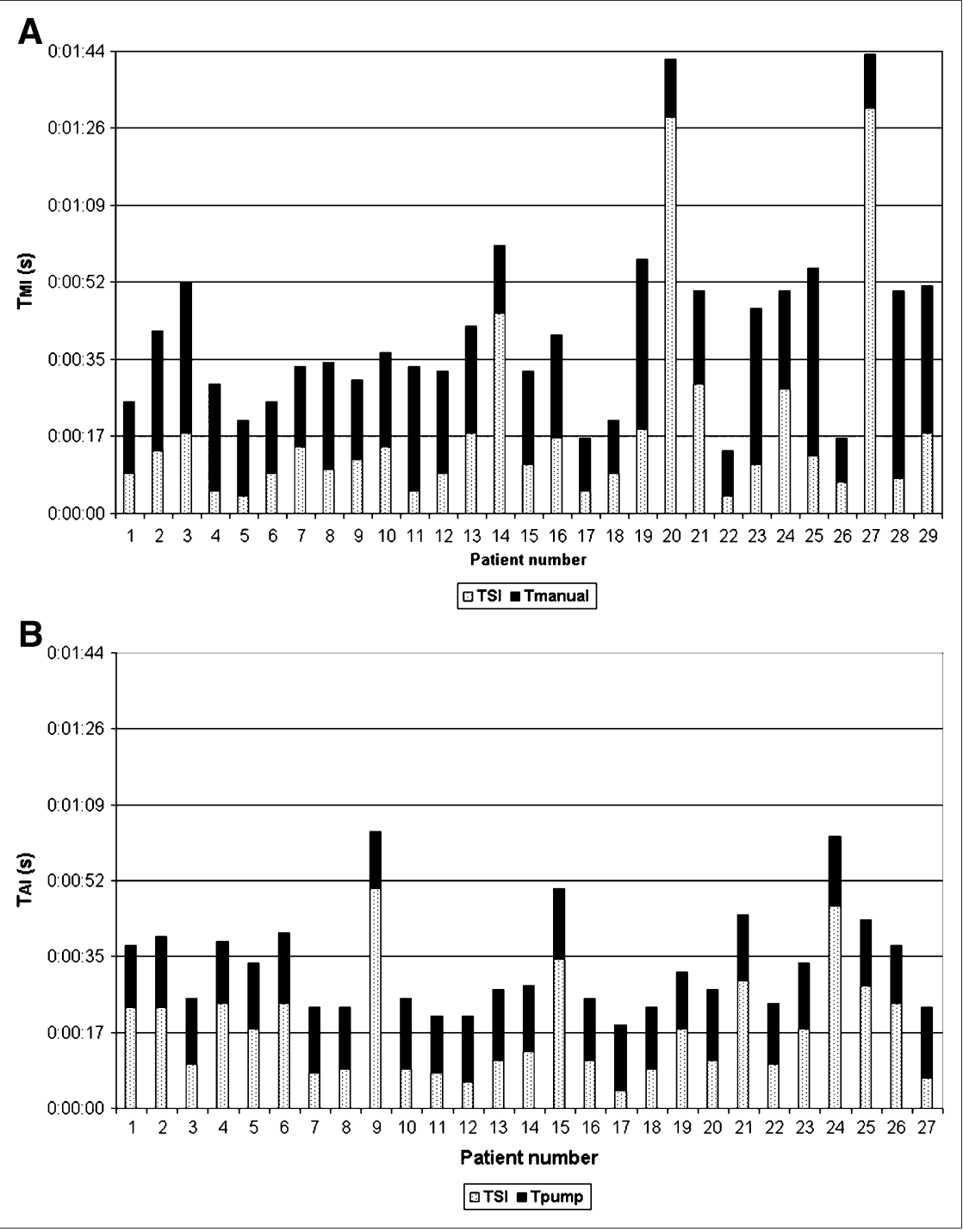

FIGURE 3. $T_{l}$ in seconds for each patient: 29 patients injected using $\mathrm{MI}\left(T_{M I}=T_{S I}+\right.$ $T_{\text {manual }}(\mathrm{A})$ and 27 patients injected using $\mathrm{Al}$ $\left(T_{A l}=T_{S I}+T_{\text {pump }}\right)(\mathrm{B})$. $\pm 22 \mathrm{~s}$, with a range of 4-91 s; with AIS, the average $T_{S I}$ was $18 \pm 12 \mathrm{~s}$, with a range of 4-50 s. This difference was not statistically significant $(P=0.85)$. However, the average $T_{\text {pump }}, 15 \pm 1 \mathrm{~s}$, was significantly inferior to the $T_{\text {manual }}$, $22 \pm 9 \mathrm{~s}(P<0.05)$ (Table 2$)$. Auras before the electroencephalogram changes were observed in 9 patients: 5 with AI (patients 1, 9, 11, 15, and 24) and 4 with MI (patients, 14, 20, 25, and 27) (Fig. 3). In patients with aura, $T_{I}$ is usually long, because $T_{S I}$ was counted from the start of the aura. Tracer injection was postictal in only 10 of 56 patients: 7 with $\mathrm{AI}$ and 3 with MI. The mean duration of seizures was shorter in the AI group of patients, but the difference was not statistically significant (Table 2), and 7 of 9 postictal AIS injections took place in seizures shorter than $17 \mathrm{~s}$.

Ictal SPECT and SISCOM demonstrated hyperperfusion that localized the seizure focus in 21 of $27(78 \%)$ patients by $\mathrm{AI}$ and in 19 of $29(65 \%)$ patients by MI, and these differences were not statistically significant $(P=0.14)$
(Fig. 4). Ictal SPECT correctly lateralized the seizure onset side but not the correct lobe in 2 patients with AI and in another 2 patients with MI. Negative and discordant results between ictal SPECT and the seizure focus were detected in 4 patients with AI. In 3 of these, SISCOM was negative, and in 1 case (patient 11), SISCOM showed ictal activity in the left frontal lobe, contralateral to the seizure focus. SISCOM with MI was normal in 4 patients and showed ictal hyperperfusion in the contralateral side in another 4 patients. In the group of 17 patients with mesial temporal lobe epilepsy, the SPECT with AI correctly localized 6 of 7 $(86 \%)$ patients and with the MI 7 of $10(70 \%)$ patients. In the 39 patients with neocortical epilepsy, SPECT with AI correctly localized 15 of $20(75 \%)$ patients, whereas SPECT with MI localized 12 of 19 (63\%) patients (Fig. 4).

\section{DISCUSSION}

The biggest drawback of ictal SPECT is that the radiotracer is given manually, a slow and complex process 
requiring dedicated personal bedside attention for extended periods. AIS was first introduced in 1998 by Sepkuty et al. (14), to optimize management of tracer injection and reduce injection latencies. However, their automatic system is based on a standard injection pump that does not provide an automatic control of dose activity. A manual self-injector was described 2 y later by Van Paesschen et al. (15). In this system, the injection is pushed manually in only $8 \mathrm{~s}$ and can be administered by the patient him- or herself. However, the system is not automated and does not calculate the volume to be injected. The third automated injection system for ictal SPECT presented in the medical literature is a CT-contrast agent injection pump adapted to inject ${ }^{99 m}$ Tc-HMPAO in a bolus (16). Remote control and a higher velocity result in a short $T_{I}$ of $17 \mathrm{~s}$. The disadvantage is that the volume to be administered must be precalculated and adjusted manually every hour to accommodate radioactive decay.

Our AIS is similar to the automated injector described by Sepkuty et al. (14). Both systems use the same pump, with a bolus injection rate of $0.333 \mathrm{~mL} / \mathrm{s}$. However, our equipment overcomes the main limitations of Sepkuty's injector system by incorporating a remote-control system and software to automatically calculate the volume injected, allowing for the radioactive decay of ${ }^{99 \mathrm{~m}} \mathrm{Tc}$.

The possible error in injected dose with MI is highly variable and depends on the moment when injection takes place (Fig. 2). On the other hand, AIS guarantees the injection of $925 \mathrm{MBq}$, with a maximum error of $\pm 3 \%$ over a 4-h period. So, for most of the time, the error in injected dose was greater for MI than for AI.

The AIS is well accepted by the nurses and electroencephalogram technologist of our unit, because the remotecontrol system reduces the level of stress produced at

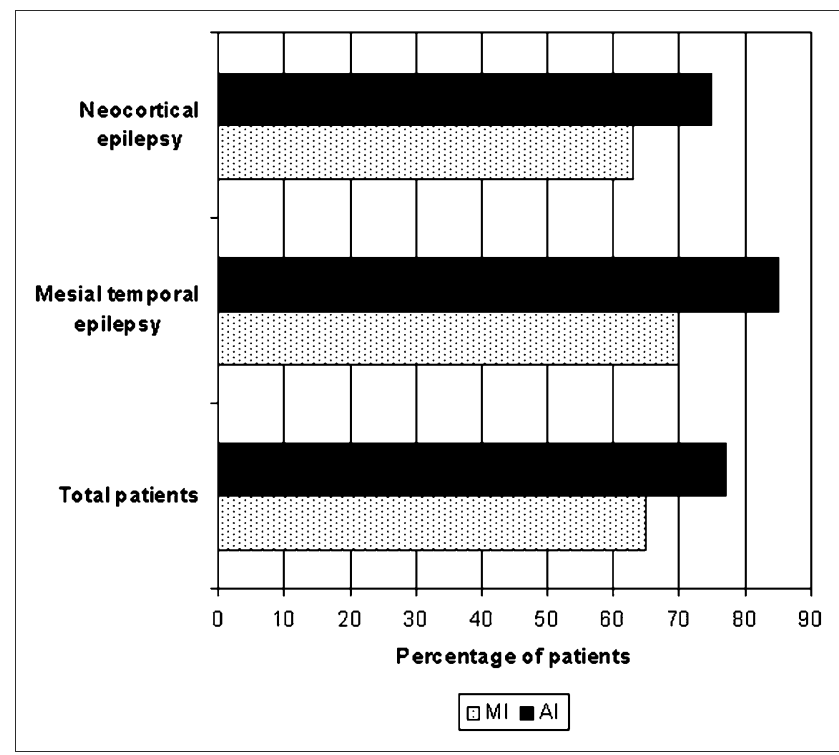

FIGURE 4. Percentages of successful seizure focus localization with ictal SPECT, using MI or AIS. seizure onset and the pump reduces the risk of radioactive contamination, as opposed to measuring a radioactive dosage manually in a hurry. An automated injection system could have other applications in the nuclear medicine department to reduce the risk of personal irradiation and contamination during injection of therapeutic doses, cardiac stress studies, and even in PET.

Our average $T_{A I}(33 \mathrm{~s})$ was faster than $T_{M I}(41 \mathrm{~s})$. Two main factors affect the equation $T_{I}=T_{S I}+T_{\text {pump }}$ or $T_{\text {manual }}$. $T_{S I}$ is extrinsic and thus variable because it depends on the electroencephalogram technician's experience and the type of seizure. However, the average $T_{S I}$ for AI (18 s) was similar to that of MI (19 s), and these differences were not statistically significant $(P=0.85)$. On the other side, $T_{\text {pump }}(15 \mathrm{~s})$ is intrinsic to the AIS, because it depends on the pump rate $(0.333 \mathrm{~mL} / \mathrm{s})$ and on an invariable dead time of the system of $4 \mathrm{~s} . T_{\text {manual }}(22 \mathrm{~s})$ is the average time that it takes the nurse to go to the patient's room, take out the syringe from the leadshielded container, and intravenously inject the tracer. Although the $T_{S I}$ of both injection systems was similar, AI was faster than MI because $T_{\text {pump }}$ is faster than $T_{\text {manual }}(P<$ $0.05)$.

Our $T_{S I}$ for AI (18 s) was higher than that of other groups $(14,16)$, because in our study the aura was included in the $T_{S I}$. In fact, as we can see in Figure $3 \mathrm{~A}$, the $T_{\text {manual }}$ of 3 patients with aura (patients 14, 20, and 27) was short, only $13 \mathrm{~s}$ on average because an aura gives the technician time to prepare the manual dose for injection once the seizure has started.

Ictal SPECT obtained with the AI detected the seizure focus more frequently than with the MI (78\% vs. $65 \%)$, although these differences were not statistically significant. The manual $T_{I}$ in our sample is short (average, $41 \mathrm{~s}$ ), thanks to the experience of our technicians in the injection of tracer under these conditions. The length of time needed for MI in epilepsy units with less experience in ictal SPECT would probably be greater.

Figure 4 shows that ictal SPECT with AI correctly localized the seizure focus, with high sensitivity in both temporal $(86 \%)$ and neocortical $(75 \%)$ epilepsy. However, when tracer was injected manually, the sensitivity of ictal SPECT remained high in temporal lobe epilepsy (70\%) but decreased in neocortical epilepsy (63\%). It seems that in neocortical seizures, which are usually shorter, ictal SPECT sensitivity is higher when AI is used.

\section{CONCLUSION}

An automated system simplifies radioactive dose injection during seizures, making this procedure more accessible. Benefits include the possibility of maintaining the tracer at the patient's bedside for a longer time, with significantly less stress for the nurses and electroencephalogram technologists and a finer adjustment of the ictal injection dose. Early results using an AIS are promising in reducing injection time and improving SPECT accuracy. A 
commercially manufactured injection system would help extend the use of ictal SPECT to more nuclear medicine departments.

\section{DISCLOSURE STATEMENT}

The costs of publication of this article were defrayed in part by the payment of page charges. Therefore, and solely to indicate this fact, this article is hereby marked "advertisement" in accordance with 18 USC section 1734.

\section{ACKNOWLEDGMENTS}

This study was partially supported by the following grants: FIS-060077 (Spanish Ministry of Science and Innovation [MICINN]), TV3-060616 (Fundació La Marató de TV3), and 2009-SGR-1049 (AGAUR Generalitat de Catalunya). No other potential conflict of interest relevant to this article was reported.

\section{REFERENCES}

1. Spencer SS, Williamson PD, Bridges SL, et al. Reliability and accuracy of localization by scalp ictal EEG. Neurology. 1985;35:1567-1575.

2. Sperling MR, Shewmon DA. General principles for presurgical evaluation. In: Engel J, Jr., ed. Epilepsia: A Comprehensive Textbook. Philadelphia, PA: Lippincott-Raven; 1997.

3. Setoain FJ, Arroyo S, Lomeña F, et al. Single photon emission computed tomography (SPECT) in a patient with bilateral temporal seizures: correlation between Ictal EEG and Postictal/Ictal SPECT. Epilepsia. 1998;39:1001-1005.
4. Dupont P, Zaknun JJ, Maes A, et al. Dynamic perfusion patterns in temporal lobe epilepsy. Eur J Nucl Med Mol Imaging. 2009;36:823-830.

5. Rosenow F, Luders H. Presurgical evaluation of epilepsy. Brain. 2001;124: 1683-1700.

6. Noachtar S, Arnold S, Yousry TA, Bartenstein P, Werhahn KJ, Tatcch K. Ictal technetium-99m ethyl cysteinate dimer single-photon emission tomographic findings and propagation of epileptic seizure activity in patients with extratemporal epilepsies. Eur J Nucl Med. 1998;25:166-172.

7. Sammaritano M, de Lotbinière A, Andermann F, Olivier A, Gloor P, Quesney LF. False lateralization by surface EEG of seizure onset in patients with temporal lobe epilepsy and gross focal cerebral lesions. Ann Neurol. 1987;21:361-369.

8. American Electroencephalographic Society Guidelines in EEG. J Clin Neurophysiol. 1986;3:133-168.

9. Ceretec ${ }^{\circledR}$ estabilizado: equipo reactivo para la preparación inyectable de exametazina de tecnecio $\left.{ }^{{ }^{99} \mathrm{~m}} \mathrm{Tc}\right)$ estabilizado con cobalto [package insert]. Little Chalfont, U.K.: Amersham Place; September 2002.

10. Mang'era KO, Vanbilloen HP, Schiepers CW, Verbruggen AM. Stabilisation of high-activity ${ }^{99 \mathrm{~m}} \mathrm{Tc}$-d,l-HMPAO preparations with cobalt chloride and their biological behaviour. Eur J Nucl Med. 1995;22:1163-1172.

11. O'Brien TJ, O'Connor MK, Mullan BP, et al. Subtraction ictal SPET co-registered to MRI in partial epilepsy: description and technical validation of the method with phantom and patient studies. Nucl Med Commun. 1998;19:31-45.

12. Hogan RE, Kaiboriboon K, Osman M. Composite SISCOM images in mesial temporal lobe epilepsy: technique and illustration of regions of hyperperfusion. Nucl Med Commun. 2004;25:539-545.

13. Ros D, Espinosa M, Setoain JF, Falcón C, Lomeña FJ, Pavía J. Evaluation of algorithms for the registration of ${ }^{99 \mathrm{~m}} \mathrm{Tc}-\mathrm{HMPAO}$ brain SPET studies. Nucl Med Commun. 1999;20:227-236.

14. Sepkuty JP, Lesser RP, Civelek CA, Cysyk B, Webber R, Shipley R. An automated injection system (with patient selection) for SPECT imaging in seizure localization. Epilepsia. 1998;39:1350-1356.

15. Van Paesschen W, Dupont P, Van Heerden B, et al. Self-injection ictal SPECT during partial seizures. Neurology. 2000;54:1994-1997.

16. Feichtinger M, Eder H, Holl A, et al. Automatic and remote controlled ictal SPECT injection for seizure focus localization by use of a commercial contrast agent application pump. Epilepsia. 2007;48:1409-1413. 